\title{
TERRITÓRIOS E ESPAÇOS VIVIDOS NO MUNICÍPIO DE
}

\author{
ITABAIANA/SE
}

\author{
AREAS AND LIVING SPACE IN THE CITY OF ITABAIANA/SE
}

\section{TERRITORIOS Y ESPACIOS VIVIDOS EN LO MUNICIPIO DE ITABAIANA/SE.}

\author{
Clêane Oliveira dos Santos \\ Mestranda do Núcleo de Pós-Graduação em Geografia \\ Universidade Federal de Sergipe \\ Rua Antônio José da Costa, 1394, Centro \\ Itabaiana, Sergipe, CEP: 49500-000 \\ E-mail: cle.ufs@hotmail.com
}

\section{Resumo}

O objetivo dessa discussão é resgatar as diferentes abordagens do território como categoria de análise da Geografia, assim como caracterizar o espaço vivido do município de Itabaiana-Se como um espaço de reprodução das relações sociais e de poder. Para tanto se resgata as diversas abordagens do conceito de território, além de enfatizar a necessidade de compreensão dos termos territorialidade, territorialização e desterritorialização. A partir de então se discute a relação existente entre território, identidade e espaço vivido no contexto da atualidade. Por fim destaca-se a caracterização histórico-geográfica dos espaços vividos do município de Itabaiana/SE, considerando que é no território que as condições de vida dos moradores de uma localidade desvendam-se através de formas e práticas diferenciadas de uso do espaço.

Palavras-chave: Geografia Cultural, Território, Espaço Vivido, Identidade

\begin{abstract}
The purpose of this discussion is to redeem the examination of the concept of territory as a category of analysis of the geography, as well as characterize the area lived in the municipality of Itabaiana as an area of reproduction of social relations and power. Thus, there recover the different approaches to the concept of territory, and emphasize the need for understanding the terms territoriality, territorial and desterritorialização. From then discusses the relationship between territory, identity and living space in the context of today. Finally there is the characterization of historical and geographical spaces of the city experienced Itabaiana / SE, whereas it is within the conditions of life of the
\end{abstract}


residents of a place reveal themselves through different forms and practices in use of space.

Keywords: Cultural Geography, Territory, Living Space, Identity

\section{Resumen}

El propósito de esta discusión es redimir el examen del concepto de territorio como una categoría de análisis de la geografía, así como caracterizar la zona vivía en el municipio de Itabaiana como un espacio de reproducción de las relaciones sociales y el poder. Por lo tanto, recuperarse enfoques diferentes del concepto de territorio, además de destacar en la necesidad de comprender los términos de territorialidad, territorial y desterritorialização. A partir de entonces se analiza la relación entre territorio, identidad y espacio vivido en el contexto de hoy. Finalmente, está la caracterización históricas y geográficas de los espacios vividos de lo consejo de Itabaiana / SE, experimentando que es dentro de lo territorio que las condiciones de la vida de los residentes de un lugar donde se revelan a través de diferentes formas y prácticas en el uso del espacio.

Palabras clave: La Geografía Cultural, Territorio, Espacio Vivido, La Identidad

\section{Introdução}

No mundo contemporâneo a diversidade territorial se manifesta a partir da produção de particularidades e singularidades, as quais estão ligadas às desigualdades do capital e a reconstrução das identidades, em função disso o espaço-tempo vivido, o território é múltiplo e complexo. Assim, o território é o local concreto da realidade da vida coletiva e é nesse território que as relações entre uma dada sociedade e a natureza se expressam e as desigualdades sociais tornam-se evidentes entre os cidadãos.

Dessa forma a configuração do território está ligada não somente aos aspectos objetivos da realidade vivida pelas populações, pois envolve também sua dimensão subjetiva, a qual aparece de modo concreto através das manifestações de sofrimento, desejos, julgamentos e expectativas.

É no momento da formação de um território que as condições de vida dos moradores de uma localidade desvendam-se através de formas e práticas diferenciadas, nas quais os fatores contribuintes, tais como, a presença ou ausência dos serviços públicos, acesso a educação ambiental, funcionam como parâmetros reveladores das desigualdades sócio-espaciais e da concepção do espaço vivido.

Assim, no espaço do cotidiano coexistem múltiplos tipos de territórios, estes aparecem tanto como forma de expressão de domínio e poder, como também na forma 
de resistência às transformações impostas por grupos dominantes, às desigualdades e conflitos sócio-econômicos e culturais.

O objetivo dessa discussão é resgatar as diferentes abordagens do território como categoria de análise da Geografia, assim como caracterizar os territórios e espaços vividos do município de Itabaiana-Se como espaço de reprodução das relações sociais e de poder, uma vez que é no território que as desigualdades sociais e, conseqüentemente, desigualdades de qualidade de vida tornam-se evidente entre os cidadãos.

Esse artigo fora segregado em quatro partes. A primeira parte denominada " $\mathrm{O}$ resgate do conceito de território" debate sobre as diversas abordagens acerca da categoria território, além de enfatizar a necessidade de compreensão dos termos territorialidade, territorialização e desterritorialização. Posteriormente, discute-se a relação existente entre território, identidade e espaço vivido no contexto da atualidade. Por fim destaca-se a caracterização histórico-geográfica dos espaços vividos do município de Itabaiana/SE.

\section{$O$ resgate do conceito de território}

A pluralidade de abordagens que visam investigar as relações do homem com seu espaço de vida e de relações permite pensar na possibilidade de identificar as representações simbólicas e seu imaginário na sua relação com a geografia. Nesta ciência o termo território é repleto de significações e por isso o conceito fora desenvolvido e analisado por múltiplos autores, os quais elucidam diferentes concepções em torno da categoria ao tratar de questões econômicas, políticas, ou culturais.

De acordo com Saquet (2009), os estudos sobre território devem reconhecer, simultaneamente, características fundamentais do processo de apropriação, dominação e produção do território assim como as relações de poder, as identidades simbólicoculturais, as contradições, as desigualdades (ritmos lentos e rápidos), as diferenças, as mudanças (descontinuidades), as permanências (continuidades), as redes de circulação, de comunicação e a natureza interior e exterior ao homem como ser genérico (biológica e socialmente). 
Assim, "nos tempos atuais o território, impregnado de significados, símbolos e imagens, perpassa a sociedade na sua prática coletiva, nas suas flexibilidades dadas pelas múltiplas apropriações temporais (...)” (FELIPE, 2001, p. 37).

A respeito dessas significações Almeida (2005) enfatiza que:

A despeito de não ser um termo próprio do vocábulo dos geógrafos, em poucos anos, território tornou-se uma das palavras-chaves na Geografia. Três idéias habitualmente são utilizadas pelos geógrafos em seus estudos espaciais: o de área dominada pelo controle territorial, o de limites face às fronteiras e àquela da dominação vinculada ao poder do governante (ALMEIDA, 2005, p. 104).

Claud Raffestin (1993) foi um dos primeiros autores a abordar a questão da diferenciação entre as categorias Espaço e Território, ao afirmar que espaço é um substrato preexistente ao território. Assim, o autor ressalta que "é essencial compreender bem que o espaço é anterior ao território. O território se forma a partir do espaço, é o resultado de uma ação conduzida por um ator sintagmático (ator que realiza um programa) em qualquer nível” (RAFFESTIN, 1993, p. 143).

No interior desse ponto de vista, o território é tratado, especialmente, com uma ênfase político-administrativa, isto é, como o território nacional, espaço físico onde se localiza uma nação, pode ser também, um espaço medido e marcado pela projeção do trabalho humano com suas linhas, limites e fronteiras. Assim, “as 'imagens' territoriais revelam as relações de produção e conseqüentemente as relações de poder, e é decifrando-as que se chega à estrutura profunda" (RAFFESTIN, 1993, p. 152).

Saquet (2009) diferencia território de espaço a partir de três características principais e diferenciadas: as relações de poder, as redes e as identidades, uma vez que o território é uma construção coletiva e multifuncional, onde sua formação envolve sempre formas areais e reticulares.

Tal diferenciação é necessária, porem é fundamental reconhecer que espaço e território não estão separados: um está no outro. O espaço é indispensável para a apropriação e produção do território (...) os conceitos não podem ser trabalhados separadamente e cada conjunção precisa ser definida por cada pesquisador ou grupo de estudos (SAQUET, 2009, p. 83).

Na obra de Manuel Correia de Andrade (1995), a idéia de poder é uma constante na análise do território, para tal autor o conceito de território não deve ser confundido 
com o de espaço ou de lugar, estando muito ligado à idéia de domínio ou de gestão de uma determinada área. Deste modo, o território está associado à idéia de poder, de controle, quer se faça referência ao poder público, estatal, quer ao poder das grandes empresas que estendem os seus tentáculos por grandes áreas territoriais, ignorando as fronteiras políticas.

Ainda de acordo com o mesmo autor a noção de território está vinculada à idéia de integração nacional, de uma área efetivamente ocupada pela população, economia, produção, comércio, transportes, fiscalização etc. Logo, no território as relações capitalistas efetivamente se fazem presentes.

De acordo com Haesbaert (2004, p. 40) existem três vertentes básicas acerca do termo. A vertente política ou jurídico - política, a mais difundida, onde o território é visto como espaço delimitado e controlado por um determinado poder relacionando, na maioria das vezes, ao poder político do Estado. A econômica enfatiza dimensão espacial das relações econômicas, onde o território é visto como fonte de recursos, como produto da divisão territorial do trabalho. E a cultural ou simbólica - cultural que dá prioridade à dimensão simbólica, subjetiva, interpretado como fruto da apropriação/valorização simbólica de um grupo em relação a seu espaço vivido.

Bonnemaison (2002, p. 126) afirma que (...) o território apela para tudo aquilo que o homem se furta ao discurso científico e se aproxima do irracional. Reflete o vivido, a afetividade, a subjetividade e muitas vezes o nó de uma religiosidade terrestre pagã ou deísta. Enquanto que o espaço tende a homogeneidade, o território indica as idéias de heterogeneidade, de etnia e de identidade cultural.

Neves (1994, p. 271) reflete que os territórios: "são espaços de ação e de poderes. Os territórios contemporâneos contêm diferentes inserções na globalidade que é historicamente fragmentada". Por isso, a globalidade se apresenta caótica, o que gera sensação de futilidade pelo desencontro entre a idéia de globalidade e a vivência angustiante de fragmentação.

Milton Santos $(1985,1996)$ também ressalta a importância da compreensão da categoria território, uma vez que é na base territorial onde tudo acontece, mesmo que as configurações e reconfigurações mundiais influenciem o espaço territorial. Assim, a periodização da história é que define como será organizado o território, ou seja, o que será o território e como serão as suas configurações econômicas, políticas e sociais. 
Assim, partindo-se de uma análise histórica "o que nos interessa é o fato de que cada momento histórico, cada elemento muda seu papel e a sua posição no sistema temporal e no sistema espacial e, a cada momento, o valor de cada qual deve ser tomado da sua relação com os demais elementos e com o todo" (SANTOS, 1985, p. 09).

Ainda de acordo com Milton Santos (1996), para se compreender a organização espacial é necessário que se interprete a relação dialética entre estrutura, processo, função e forma. Forma se caracteriza pelo aspecto visível de um objeto ou arranjo de objetos que constitui um padrão espacial. Função seria a tarefa, atividade ou papel a ser desempenhado pelo objeto criado. Estrutura diz respeito à maneira como os objetos estão inter-relacionados. E o processo configura-se na ação que se realiza continuamente, visando um resultado.

Parafraseando o autor "podem as formas, durante muito tempo, permanecer as mesmas, mas como a sociedade está sempre em movimento, a mesma paisagem, a mesma configuração territorial, nos oferecem, no transcurso histórico, espaços diferentes" (SANTOS, 1996, p. 77).

Em $O$ retorno do território de 1994, Santos diz que o território é resultante da nova construção do espaço ou da totalidade, e do novo funcionamento do território através das verticalidades e horizontalidades. Essas correspondem aos domínios de contigüidade, de lugares vizinhos, reunidos por uma continuidade territorial. Aquelas seriam formadas por pontos distantes uns dos outros, ligados por todas as formas e processos sociais, ou seja, ligados pela proximidade organizacional, por ações hierarquizadas, onde o processo vertical dá-se através a partir de redes que atuam numa escala mundial a favor dos atores hegemônicos.

Integrada ao território, tem-se a expressão territorialidade que "pode vir a ser encarada tanto como o que se encontra no território, estando sujeito à sua gestão, como, ao mesmo tempo, o processo subjetivo de conscientização da população de fazer parte de um território, de integrar-se em um Estado" (ANDRADE, 1995, p. 20).

A formação de um território dá às pessoas que nele habitam a consciência de sua participação, criando o sentido da territorialidade que, de forma subjetiva, cria uma consciência de confraternização entre elas. Assim, "la territorialidade, como la cualidad subjetiva, del grupo social o del individuo, que Le permite en base a imágenes, 
representaciones y proyectos tomar conciencia de su espacio de vida" (CARA, 1995, p. $67)$.

Segundo Bonnemaison (2002, p. 107), a territorialidade de um grupo ou de um indivíduo não pode se reduzir ao estudo de seu sistema territorial. A territorialidade é a expressão de um comportamento vivido: ela engloba, ao mesmo tempo, a relação com o território e, a partir dela, a relação com o espaço "estrangeiro". Ela inclui aquilo que fixa o homem aos lugares que são seus e aquilo que o impele para fora do território, lá onde começa "o espaço".

Assim o mesmo autor conclui que a territorialidade pressupõe uma oscilação continua entre o fixo e o móvel, ou seja, entre aquilo que transmite segurança, símbolo de identidade, e o espaço que se abre para liberdade, muitas vezes para alienação.

Dessa forma, o referido termo corresponde ao controle sobre uma área ou espaço, representa uma estratégia para controlar os recursos, fenômenos, relações e pessoas, estando, assim, intimamente, relacionado ao modo como as pessoas usam a terra, organizam o espaço e atribuem significado ao lugar (SAQUET \& SPOSITO, 2008).

A posição de Raffestin acerca da territorialidade é diferente, já que a considera como um conjunto de relações que nascem em um sistema tridimensional sociedadeespaço-tempo, em função da maior conquista possível de autonomia, compatível com os recursos de um sistema (DEMATTES, 2008).

São duas visões divergentes de considerar o local e as relações com o território dos sujeitos. Destaca-se a territorialidade passiva e a ativa. A primeira objetiva excluir sujeitos e recursos, e a segunda, inclui sujeitos e recursos, pois deriva das ações coletivas no processo de territorialização.

O termo territorialização é a forma de como se materializa o território, bem como a manifestação das pessoas, a especialização de qualquer segmento da sociedade como, por exemplo, a produção econômica de um determinado produto.

Nas palavras de Rogério Haesbaert (2004, p. 247) a territorialização:

[...] também pode ser vista ainda hoje para alguns grupos como agricultores pobres ou nações indígenas expropriadas, como a busca de terras agricultável ou que disponha dos recursos mínimos requeridos à sobrevivência do grupo. Os migrantes estão juntamente nesta condição. Migram para encontrar terras que possam utilizar [...] 
e através das quais possam reconstruir ou manifestar sua identidade cultural (dimensões simbólicas ou expressivas do território).

Outro debate teórico sobre o território envolve o termo desterritorialização que pode ser considerado um fruto das relações sociais e de poder, "é uma das forças básicas do mundo moderno" (APPADURAI, 1994, p. 318), onde as pessoas se mobilizam pelo mundo em função das necessidades criadas pela transformação da produção. Assim tal dinâmica está vinculada a questão do fluxo da economia cultural global.

Nesse contexto Rogério Haesbaert (2002, p. 29-30) identifica através de um balanço das principais interpretações a desterritorialização, como domínio das redes, da mobilidade; como perda de referenciais espaciais, concretos, sob domínio das relações imaterias; como perda do poder em termos de controle dos processos sociais através do espaço, principalmente o enfraquecimento do território dos Estados-nações; como a deslocalização da economia, a libertação dos principais fatores locacionais, o que favorece o deslocamento e localização de corporações transnacionais em vários lugares; e como fruto da crescente homogeneização cultural do planeta.

Logo, ainda segundo Haesbaert (2002, p. 36), a desterritorialização "antes de significar desmaterialização, dissolução das distancias, deslocalização das firmas ou debilitação dos controles fronteiriços, é um processo de exclusão social”.

O território, interpretado como um espaço que não pode ser considerado nem natural e nem estritamente político, econômico ou cultural, é definido em função da perspectiva integradora entre as diversas esferas sociais, desempenhando um pouco do papel que cabe a região. Porém de qualquer forma o território caracteriza-se pela referência às relações sociais e ao contexto histórico em que está engajado, mas vale lembrar que a leitura integradora só é possível se houver uma articulação do local ao global. Assim, o local:

Está vinculado aos processos gerais de heterogeneização/diferenciação (frente a um global de tendências homogeneizadoras e universalizantes); o local como instrumento de analise, escala geográfica de abordagem (envolvendo as relações sociais ligadas ao cotidiano e aos contatos face-a-face); o local como lugar (este geralmente entendido como espaço culturalmente significativo, dotado de valor subjetivo) (HAESBAERT, 1999, P. 26). 
Nessa perspectiva a diversidade territorial é fruto da interação entre as dimensões global/universal e a local/particular. Porém, "a produção da diversidade territorial, embora manifeste uma tendência a ocorrer cada vez mais nos circuitos que vinculam escala local e escala global, na verdade continua se dando em múltiplas escalas" (HAESBAERT, 1999, p. 28).

Neste contexto, é importante destacar que tanto os processos culturais inerentes às relações de poder como as identidades simbólico-culturais mais especificas, sobretudo os processos de TDR (territorialização, desterritorialização e reteritorialização), são aspectos empregados em estudos de geografia quando se destaca o conceito de território, juntamente com relações econômicas e políticas (de poder), as redes e a natureza exterior ao homem (SAQUET, 2009).

A abordagem territorial representa uma nova forma de ver o espaço, a sociedade e a natureza, isto é, a dinâmica socioespacial, em vista das redes de circulação e comunicação, das relações de poder e das identidades historicamente construídas. Logo, as concepções apresentadas não são fechadas, uma vez que a formação e a apropriação territorial é um processo complexo, sendo possível identificar variáveis de diferentes vertentes e estabelecer conexões entre as mesmas.

\section{A relação entre territórios, identidades e espaços vividos}

A análise combinada entre os aspectos ambientais, sociais e culturais numa localidade é importante para o estabelecimento de medidas que possibilitem condições dignas de vida à população uma vez que a materialização do econômico e do sóciocultural, que se sobrepõem ano após ano, não deve ser dissociada do quadro natural, o qual é uma realidade ambiental com ativa participação social.

Carlos (2004) afirma que a atividade social tem o espaço como condição de sua consumação. O espaço é o palco da prática social, é através disso que o espaço se torna território. Deste modo, a reprodução das relações sociais materializa-se num espaço apropriado para este fim. "A vida, no plano cotidiano do habitante, constitui-se no lugar produzido para esta finalidade, e nesta direção, o lugar da vida constitui uma identidade habitante-lugar" (CARLOS, 2004, p.47).

O espaço apropriado, lugar produzido do qual fala a autora, é o que pode ser entendido como território se for levado em consideração o fator da territorialidade, 
aspecto que possibilita a construção da identidade do cidadão com um lugar, de sentirse parte daquilo que lhe pertence.

Nesse sentido, território possui tanto uma componente relativa ao espaço social, como ao espaço vivido. O espaço social refere-se à objetividade das relações sociais e entre os homens e o espaço. Contudo, o espaço vivido compreende a relação existencial que o sujeito estabelece com tudo que há no espaço de seu cotidiano.

De acordo com Saquet (2009) o território do cotidiano corresponde a territorialização de nossas ações de todos os dias a partir do qual garantimos nossa satisfação das necessidades, isto é, é o espaço onde se estabelece relações entre indivíduos e lugares.

Aqui o cotidiano é interpretado como ponto de partida para a reflexão do território e das representações, como produtor da sociabilidade e base da identidade. Onde o mundo das representações que mediam o cotidiano depende amplamente da informação e dos meios de comunicação de massa, os quais geram conflitos e alienação, por isso o cotidiano é ao mesmo tempo o interior percebido e a informação externa que conduze a capacidade de interpretação dos processos sócio-territoriais (CARA, 1995).

A identidade representa a fonte de significação e experiência de um povo, construída num contexto marcado por relações de poder. Segundo Saquet (2007), “a identidade tem sido tratada de diferentes maneiras em estudos do território, especialmente, como continuidades histórico-culturais, simbólicas, inerentes à vida de um certo grupo social em um determinado lugar" ( SAQUET, 2007, p. 147).

Castells (1999) ressalva a existência de identidades múltiplas ao trabalhar a questão das distintas formas e origens de construção das identidades, visto que as diferenças estão estritamente vinculadas a um dado contexto social.

Não obstante, as transformações pelas quais a sociedade está passando tem ocasionado uma mudança nas identidades pessoais, ocasionando um deslocamento dos indivíduos de seu lugar no mundo social e cultural e de si mesmos, gerando assim uma crise de identidade (HALL, 2006).

A abordagem de Hall (2006) está assentada em torno da chamada crise de identidade do mundo pós-moderno, a qual é compreendida como parte de um processo mais amplo de mudança, que acaba por deslocar as estruturas e os processos centrais 
sobre os quais se estruturavam as sociedades modernas, e tendem à um abalo nos quadros de referência que davam aos indivíduos uma fixação estável no mundo social.

De acordo com Almeida (2005) a identidade representa um conjunto de características e circunstancias que são distintas de um individuo para o outro, concebidas por situações que se diriam culturais na medida em que representam momentos e territórios característicos de um grupo social sobre espaços e temporalidades determinadas.

A identidade, portanto, não é algo pronto e acabado, representa um processo onde os indivíduos passam a se identificar, aos poucos, com um dado comportamento ou circunstancia cultural, social, política e econômica, que se dá por meio da comunicação com outros atores (diálogo e confronto). A territorialidade é expressão deste processo no cotidiano dos atores sociais.

Estabelecemos relações econômicas, políticas e culturais todos os dias, minuto a minuto, entre nós e com a natureza exterior (inorgânica), o que pode ser traduzido pelas diferenças, identidades e desigualdades, ou seja, pelas territorialidades cotidianas: todos processos espaço-temporais e territoriais inerentes a nossa vida na sociedade e na natureza ( SAQUET, 2009, p. 85).

Pode-se afirmar que a identidade está vinculada profundamente ao processo de representação, onde a construção e desconstrução das relações espaço-tempo no interior dos diferentes sistemas de representação têm efeitos profundos sobre a forma como as identidades são localizadas e representadas.

Nesse contexto, os símbolos, imagens e aspectos culturais são valores que para a população local materializa uma identidade incorporada aos processos cotidianos dando um sentido de território, de pertença e de defesa dos valores, do território, da identidade, utilizando-se da vertente político-cultural, a qual se constitue em relações de poder e defesa de uma cultura adquirida ou em construção.

Segundo Morelli e Suertegaray (2009), a identidade com o território promove a interação entre um grupo de pessoas com idéias e pensamentos comuns, fortalecendo a memória coletiva, sendo esta formada por um conjunto de referências históricas comuns gerando o sentimento de pertencimento, motivando a identidade com o território. Porém, também, contribuem para a formação da identidade coletiva, as lembranças contidas na memória individual. 
Essa relação identidade-território toma forma de um processo em movimento, que se constitui ao longo do tempo, tendo como principal elemento o sentido de pertencimento do indivíduo ou grupo com o seu espaço de vivência. Esse sentimento de fazer parte do espaço em que se vive, de conceber o espaço como lócus das práticas, onde se tem o enraizamento de uma complexa rede de sociabilidade é que dá a esse espaço o caráter de território.

Para ocorrer uma relação entre identidade, cidadão e lugar é necessário que o indivíduo ou grupo desfrute das condições de cidadania, nas quais os direitos sejam consolidados no espaço. Compreende-se que isso não é possível, por exemplo, a um indivíduo ou grupo desprovido de garantias sociais, carência em termos de educação, saúde, moradia, entre outros, a exclusão das condições de reprodução da vida.

Desse modo, o individuo excluído dos direitos a uma vida em sociedade, negada enquanto cidadão passa a fazer parte de uma exclusão sócio-territorial, fato que se origina da negação as suas relações com o espaço social e vivido. Em muitos casos, a perda dos mecanismos de realização da cidadania, exclui o individuo da possibilidade de apropriação do espaço, uma das formas de manifestação do território.

Esse pensamento vai de acordo com as palavras de Koga (2003, p. 33): “O território também representa o chão da cidadania, pois a cidadania significa vida ativa no território onde se concretizam as relações sociais, as relações de vizinhança e solidariedade, as relações de poder [...]"

A cidadania só pode existir para indivíduos em condições de vivência na sociedade, não podendo ser exercida por pessoas excluídas socioespacialmente e por aquelas que não participam do dos interesses e necessidades da coletividade, nem tampouco do acolhimento a sua significação e valores. Logo, cidadania tem a ver com a identidade e o pertencimento a uma coletividade, a um território.

Ao estudar as necessidades fundamentais e usos do território Carlos (2000) distingue dois argumentos básicos. O do produtor que necessitará de equipamentos de infra-estrutura, de informações, de inovação, de amplas instalações. E a do cidadão que se apropria do espaço em função das necessidades inerentes à reprodução da vida: o habitar e o trabalho, incluindo o lazer. Para isso, precisa de equipamentos de lazer, oferta de determinados bens e serviços coletivos, de cultura, enfim elementos que proporcionem uma melhor qualidade de vida para o cidadão. 
Segundo Koga (2003) o território é um fator dinâmico no processo de exclusão/inclusão social, nele as desigualdades sociais tornam-se evidente entre os cidadãos, as condições de vida entre os moradores de uma mesma cidade mostram-se diferenciadas, a presença/ausência de serviços públicos se faz sentir e a qualidade destes mesmos serviços apresenta-se desiguais.

Assim, no final dos anos de 1990 novas metodologias introduziram a relação espaço, território e meio ambiente nos estudos sobre condições de vida as quais não devem ser estudadas deslocadas das condições do meio onde se vive, seja este uma zona urbana ou rural, um bairro ou um povoado. Logo, "cada lugar possui uma história que lhe é muito peculiar, criando uma identidade entre seu espaço e o espaço da cidade como um todo" (KOGA, 2003, p. 134).

Por isso, entende-se que o espaço está incorporado ao cotidiano das pessoas, é produzido e re-produzido a todo instante em decorrência das necessidades humanas daquele momento, geridas principalmente pelo capitalismo, mas determinado pelo modo de vida das pessoas, as quais constroem o espaço vivido.

\section{Discussão dos espaços vividos em Itabaiana/SE}

Nesta pesquisa, a questão territorial não se limita à adoção de uma divisão física, pois, como já foi discutido, a divisão territorial implica um processo que vai além do aspecto técnico-administrativo, sendo também um fator político, econômico e cultural. Já que quanto melhor se conhece o espaço onde se vive, maiores são as possibilidades de seus moradores intervirem no mesmo, configurando, dessa forma, o espaço vivido. Assim, a dimensão econômica, política, cultural e a natureza formam uma intricada configuração onde o território surge como elemento que dá unidade a ação dos sujeitos sociais.

A formação territorial sergipana e, conseqüentemente a Itabaianense ${ }^{1}$, passa por diversos momentos. Inicialmente capitania da Bahia, teve sua extensão conquistada pelo português Cristóvão de Barros no ano de 1590. Deste marco histórico, a colonização se efetiva com a destruição dos indígenas e a doação das primeiras

\footnotetext{
${ }^{1} \mathrm{O}$ município de Itabaiana situa-se numa latitude $10^{\circ} 41^{\prime} 06^{\prime \prime}$ Sul e a uma longitude $37^{\circ} 25^{\prime} 31^{\prime \prime}$ ' Oeste, estando a uma altitude de 188 metros. Localiza-se na região central do estado de Sergipe/NE, ocupa uma área de 364 quilômetros quadrados.
} 
sesmarias que se destinavam à produção de subsistência e criação de gado. No entanto, este processo é desarticulado pela invasão holandesa, que destrói a economia nascente. Somente em meados do século XVIII, a economia volta a se estabelecer com a produção açucareira, ainda vinculada a capitania baiana.

Do desenlace histórico sergipano, destacar-se-á no chamado Agreste da província, o espaço de Itabaiana, que no século XVI se estabeleceu como "Caatinga de Ayres da Rocha". No contexto dessa ocupação, por meio de doações, é que os agraciados com sesmarias irão fundar o Arraial de Santo Antônio no local conhecido hoje como Igreja Velha.

A sede deste município se encontrava numa área que correspondia ao sítio do pároco de São Cristóvão, Pe. Sebastião Pedroso de Góes, que a vendeu em 9 de Julho de 1675 a Irmandade das Almas de Itabaiana para se construir um santuário em homenagem a Santo Antônio. Com a venda do terreno "Caatinga" de Ayres da Rocha, foi erguida a Igreja de Santo Antônio e Almas de Itabaiana, que ficou pronta em 30 de outubro de 1675 (CARVALHO, 1973).

Em 1698, o arraial de Itabaiana fora elevado a categoria de vila pela portaria de D. João de Lancaster, que foi conduzido ao Ouvidor D. Diogo Pacheco de Carvalho, denominando-a de Vila de Santo Antônio e Almas de Itabaiana. Em 1727, aparecia como já possuindo sua Câmara, representando o respectivo município, criado em 1698, sendo elevada a cidade pela resolução provincial $n^{\circ}$. 1331, de 28 de agosto de 1888 , que já em 1859 havia mudado de nome para, apenas, Itabaiana.

Neste mesmo século, a Resolução Provincial no 569 cria a comarca de Itabaiana, que por esta ocasião e também pela conjuntura de desmembramento da comarca de São Cristóvão, acontece à perda da Freguesia de Campo do Brito² .

$\mathrm{Na}$ nova configuração territorial itabaianense sobressaía-se casas de fachadas pouco atrativas e pobres. Dessa forma, a população que residia nas aglomerações urbanas, continuava dependendo do meio rural, ou tinha cargos judiciários e administrativos, uma vez que, a sede municipal itabaianense representava um prolongamento das atividades rurais (CARVALHO, 2000).

\footnotetext{
${ }^{2}$ Na década de 1910 ocorreu a emancipação da Freguesia de Campo do Brito, que pela Lei 624 de 29 de outubro de 1912, cria o município, o qual era grande contribuinte em impostos e grande detentor de extensões territoriais, subordinadas a Itabaiana.
} 
No início do século XX, e a partir do Decreto Lei $n^{\circ}$ 69, de 28 de março de 1938, o município de Itabaiana passa a compor-se de apenas um distrito, o da cidade de igual nome. Itabaiana se apresentava com três praças, da Matriz, Santa Cruz e Largo Santo Antônio.

Em meados de 1950, a cidade de Itabaiana tomará um aspecto urbano mais consolidado. Governada inicialmente por Euclides Paes Mendonça, que intensifica o número de ruas e de suas dimensões, tornando-as mais largas, contrariando a estrutura da área central da cidade, que ainda hoje é constituída por ruas estreitas, permanecendo como um retrato da herança colonial. A partir de 1960, esta cidade teve um crescimento urbano desordenado ${ }^{3}$.

O espaço vivido de Itabaiana é considerado ao mesmo tempo fruto concreto de um processo histórico onde há uma dimensão real ou física e uma construção simbólica que articula sentidos e idéias. Em virtude da singularidade na construção da identidade territorial de Itabaiana, pode-se dizer que na estrutura espacial de tal município existem recortes territoriais distintos, porém complementares. Os espaços vividos do recorte municipal como um todo e da área urbana.

Ambos apresentam características singulares, em função da dinâmica rural e urbana que se estabelece em cada um, dessa forma nem todos habitantes do município estabelece relações de pertencimento, com algum povoado ou com a cidade, pois o "território ele o é, para aqueles que têm uma identidade territorial com ele, o resultado de uma apropriação simbólico-expressiva do espaço, sendo portador de significados e relações simbólicas" (ALMEIDA, 2005, p. 108).

Nessa perspectiva o município de Itabaiana apresenta uma representatividade simbólica ligada à questão de sua importância enquanto centro comercial e distribuidor de serviços, de saúde e educação, na região do Agreste sergipano. Desse modo, Itabaiana constitui um espaço vivido onde as características identitárias do itabaianense são reconhecidas em virtude da aptidão comercial (formal e informal), do caráter empreendedor, do entusiasmo pela educação superior, enfim uma série de atribuições que são reconhecidas mesmo em outras localidades.

\footnotetext{
${ }^{3}$ De acordo com a contagem da população (IBGE, 2007) o município apresentava uma população de 85.725 habitantes, 62.777 habitantes na área urbana e 20.384 habitantes na área rural. Vale ressaltar que de acordo com o IBGE (2009) estima-se que o número de população passou para 86.564 habitantes.
} 
O reconhecimento do itabaianense em áreas distintas do território sergipano e nordestino pode está vinculado ao sentimento topofílico que define o apego ao lugar por ser familiar, representando o passado e evocando o orgulho e o patriotismo dando ênfase as raízes de um povo.

Aqui a topofilia compreende as maneiras como os seres humanos respondem ao meio ambiente e que podem variar, desde a apreciação estética até o contato corporal. Nesse ensejo é importante destacar que nos espaços rurais e urbanos de Itabaiana aflora um sentimento topofílico bastante expressivo ligado a questão da pequena dimensão espacial. Segundo afirmações de Tuan (1980), a verdadeira topofilia se pratica em dimensões espaciais reduzidas e homogêneas, visto que é mais fácil as pessoas se identificarem e se afeiçoarem a elas, do que em dimensões amplas e heterogêneas do espaço.

Itabaiana é, dentro do contexto sócio-econômico do Estado, uma área de destaque. Esta situação é produto da capacidade comercial que este sempre obteve, desde sua formação econômica. Isso ocasionou uma forte atração populacional em busca de melhores condições de vida, resultando num aumento considerável no número de habitantes em condições precárias nas periferias da cidade.

Pode-se dizer que nas áreas periféricas da cidade tem-se a constituição de um espaço vivido divergente daquele que está consolidado no centro da cidade. São áreas onde a exposição à violência, a falta de saneamento e educação ambiental se dão com maior intensidade e aspereza. Fatos que contribuem para um nível baixo de qualidade de vida em virtude da exposição a riscos socioambientais. Nesses espaços as relações sociais estabelecidas apontam para características identitarias particulares, são outros modos de sobreviver, de agir, de enxergar o mundo.

Por sua vez, entre os espaços do perímetro urbano e rural configuram-se relações sociais divergentes daquelas estabelecidas entre o centro e periferia do município, já que neste caso não se percebe o sentimento de repulsa, mas de pertencimento. Tal fato pode estar ligado à questão da proximidade e facilidade de transporte do espaço rural para o urbano em Itabaiana contribui para elevar a influencia dos serviços e atividades oferecidos na cidade aos produtores do campo.

Essa influencia da cidade sobre o campo vem atrelada às necessidades de conforto, a segurança, a melhoria na qualidade de vida e, por conseguinte, a formação 
singular da identidade, a qual "se refere à vida em sociedade, a um campo simbólico e envolve reciprocidade. Na geografia, significa, simultaneamente, espacialidade e/ou territorialidade" (SAQUET, 2007, p. 147).

Do mesmo modo que a maior parte dos municípios de Sergipe, Itabaiana apresenta deficiência hídrica ${ }^{4}$ quase todo o ano, principalmente na primavera e verão, no entanto ocorrem excedentes de chuvas nos meses de maio, junho e julho, período em que se observa um decréscimo de temperatura que se prolonga até final do mês de agosto.

Nos últimos trinta anos o município de Itabaiana foi sede da consolidação de algumas políticas territoriais, como a construção de três barragens: Açude da Marcela, Jacarecica I e Porção da Ribeira (figura 01), localizadas respectivamente no rio Jacarecica que contribui para formação do lago da barragem que leva seu nome e afluentes da Bacia do Rio Sergipe ${ }^{5}$. Esses rios contribuem para o dinamismo da atividade agrícola no município, pois propiciaram a construção das três referidas barragens objetivando a implantação da agricultura irrigada.

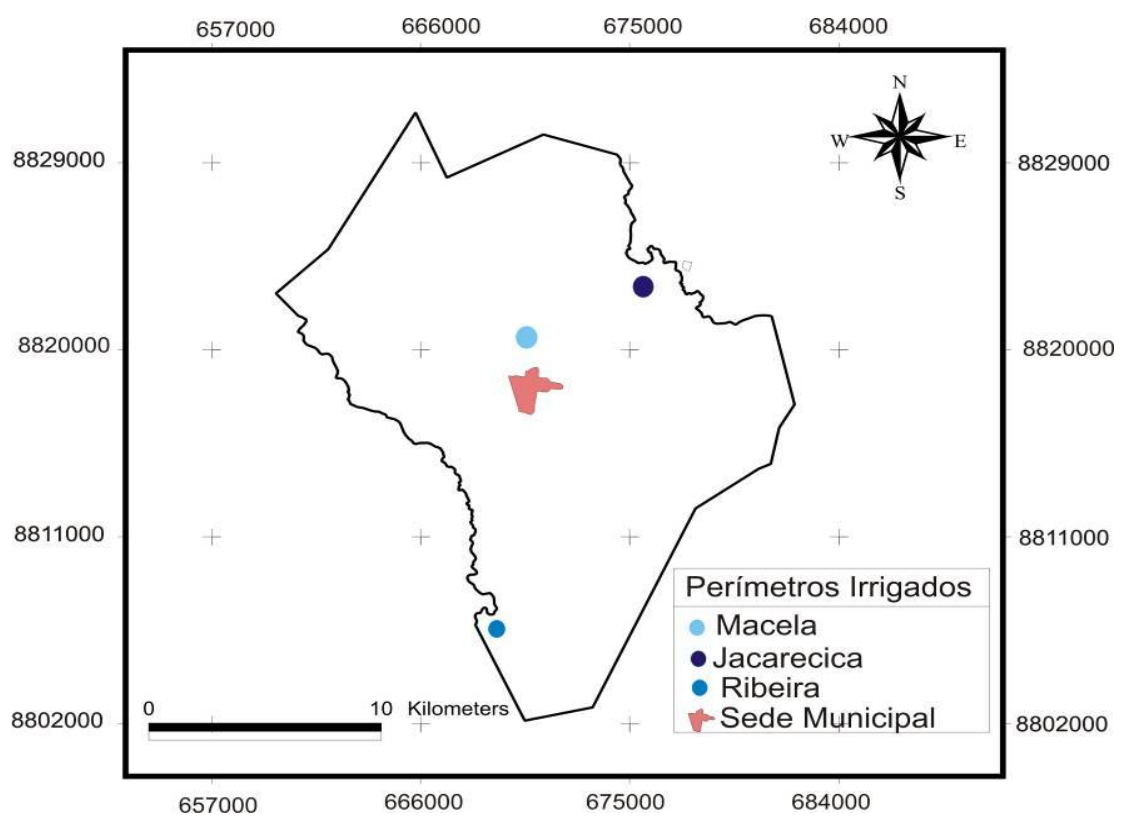

Figura 01. Localização dos perímetros irrigados do município de Itabaiana-SE. Organização: Diana M. de Carvalho, 2008.

\footnotetext{
${ }^{4}$ Segundo a SEPLANTEC/SUPES, 1997/2000, o município está parcialmente inserido no polígono das secas, configurando-se numa região de transição climática, o agreste sergipano, fato que a torna peculiar no contexto de Sergipe, pois apresenta vulnerabilidades ambientais.

${ }^{5}$ Além desses rios, o município é drenado pela bacia do Vaza-Barris, rio que atravessa Sergipe no sentido oeste-leste e que, em Itabaiana tem como afluentes o rio das pedras, o rio Tabocas e o rio Traíras
} 
Por estes projetos, Itabaiana tem diversificado sua produção, como também tem sediado espaços de armazenamento, e o estado tem obtido auto-suficiência na maior parte dos produtos olerícolas consumidos, uma vez que, estas deram possibilidades de implantação de sistemas de irrigação, a difusão de insumos modernos e pacotes tecnológicos. De acordo com Silva (2001, p.07) "esses projetos foram concebidos com o propósito de aumentar a oferta de alimentos, criando assim, um fortalecimento seletivo de espaço e de culturas, melhorando a qualidade de vida do pequeno produtor olerícola".

O açude da Macela está localizado no espaço urbano do município, no bairro que leva seu nome. Os outros dois perímetros estão localizados no espaço rural. Porém os três apresentam uma organização espacial, social e cultural próprio. No município de Itabaiana os espaços ocupados pelos perímetros irrigados se constituem em espaços vividos em decorrência das particularidades identitárias, forma de vida e representações definidoras de tal espaço, que pode ser considerado um território de fronteira, o qual delimita a realidade dos perímetros da realidade dos demais espaços vividos do município.

Essa definição dos territórios de fronteira está ligada aos sistemas de significados que se intersectam, onde as ações simbólicas cotidianas são a segurança da continuidade do grupo social que já estava situado no local e servem para delimitar e reproduzir as fronteiras culturais com outros grupos em função do acesso desigual aos símbolos.

Nas palavras de Almeida (2005, p. 107), “a forma de representações da fronteira é desigual entre os diversos segmentos ali presentes; cada representação corresponde a um interesse diferente (...) a fronteira tende a provocar a dicotomia entre as identidades territoriais, pois ou é deste território ou não é”.

Vale salientar que a partir da introdução de todo aparato modernizador da produção agrícola ocorreram mudanças de comportamento e na cultura dos produtores do município, já que as relações com o mercado passaram a ser mais constantes e participativas.

Esse fato está vinculado, também, à questão da relação de trabalho que é estabelecida nos perímetros onde se destaca uma produção por contrato junto às grandes atacadistas de supermercados, verificando-se uma maior participação da mão-de-obra 
assalariada, uma vez que se fornecem produtos diariamente. Porém, "face às limitações econômicas dos produtores e o alto custo de implantação e operacionalização de um poço, as áreas irrigadas individuais são relativamente pequenas" (SILVA, 2001, p.63).

Dentre os perímetros irrigados, na localidade do Açude da Macela encontra-se um maior número de agricultores alfabetizados, pois como o açude localiza-se próximo a cidade existe um maior acesso as escolas. No entanto, o povoado Cajaíba pertencente à Porção do Ribeira, apresenta um alto índice de analfabetismo entre os agricultores, em função de um grande número de pessoas idosas na localidade.

Face a falta de instrução e ao tipo de estrutura produtiva adotada nos perímetros ocorre o uso indiscriminado de agrotóxicos como o DITHANE, DECIS E POLYTIM, visto que os produtores não tomam medidas preventivas à contaminação durante a aplicação do veneno e nem fazem uso de algum tipo de equipamento de proteção individual, tais como luvas, botas, mascaras, capacete, etc. Esse processo resulta na constante ocorrência de casos de intoxicação de grande parte dos agricultores que são atendidos no hospital regional de Itabaiana.

Silva (2001, p. 88) ressalta que o baixo nível de instrução se antepõe como uma barreira ao produtor na labuta com a burocracia estabelecida nos órgãos de assessoramento da produção, comercialização e credito bancário. Tal grau de instrução limita o uso correto do progresso técnico, inibindo também a iniciativa do agricultor em procurar assistência técnica formal.

Nas palavras de Borges (1995, p. 72):

O uso indiscriminado de agrotóxicos na área do açude da Macela vem gerando um custo social e ambiental muito grande, pois nesse ecossistema existe uma forte disseminação de pragas e doenças, o que torna, hoje, praticamente impossível a produção sem o uso de agrotóxicos.

Assim, o município de Itabaiana destaca-se como um importante recorte territorial dentro do estado de Sergipe, pois como organização do espaço, o território responde, em sua primeira instancia, a necessidades econômicas, sociais e políticas da sociedade e, por isso, sua produção está sustentada pelas relações sociais que o atravessam. 


\section{Considerações finais}

A visão alternativa da geografia cultural traz contribuições bastante relevantes para a configuração do conhecimento geográfico, se não, pelo menos instiga novas percepções acerca do espaço vivido. Assim, na análise do espaço vivido a objetividade não provém de regras exatas de observação, porém do uso plausível das várias explanações na procura de se compreender o comportamento social dos atores no espaço.

Para fins de conclusão, destaca-se que as representações estão intimamente associadas a símbolos e que a criação de símbolos não é arbitrária. Nesse contexto é importante destacar que a construção da identidade está vinculada a percepção, uma vez que muito do que percebemos tem valor para nós, para a sobrevivência biológica, e para propiciar algumas satisfações que estão enraizadas na cultura. $\mathrm{O}$ ser humano, com o objetivo de atender suas necessidades e desejos, está constantemente agindo sobre o meio, construindo novos territórios.

Conforme já foram citadas as territorialidades são geradas pelo processo de territorialização, isto é, apropriação do espaço geográfico - e ensejam identidades - no sentido de construção e pertencimento de um lugar. Nesse sentido recentemente o conceito de território foi reformulado e passa a ressaltar a identidade espacial, compreendida como um resultado da apropriação simbólica do espaço, percebido como território.

Logo, a formação e compreensão dos espaços vividos no município estão ligadas aos múltiplos níveis de análise que permitem a compreensão do território Itabaianense, fato que nos possibilita cogitar a existência de territórios distintos devido à presença de características peculiares que os definem nas pequenas dimensões espaciais do município. Contudo, a formação dos territórios não se reduz a dimensão econômica, é também objeto de intervenções simbólicas e é essa base territorial que os itabaianenses cogitam suas concepções de mundo.

\section{Referências Bibliográficas}

ALMEIDA. M. G. de. Fronteiras, territórios e territorialidades. Revista da ANPEGE. Ano 2, n. 2. Fortaleza: 2005, p. 103-114. 
ANDRADE, Manuel Correia. A questão do território no Brasil. São Paulo: Ucitec; Recife: IPESPE, 1995.

APPADURAI, A. Disjunção e diferença na economia cultural global. In: FEATHERSTONE (coord.). Cultura global: Nacionalismo, globalização e modernidade. Petrópolis: Vozes, 1994.

BORGES, S. dos S. Agrotóxicos, sociedade e Natureza: A problemática do perímetro irrigado da Macela-SE. Dissertação de mestrado: Núcleo de pós-graduação em Geografia, UFS, 1995.

BONNEMAISON, Jòel. Viagem em Torno do território. In: CORREAA, Roberto Lobato; ROSENDAHL, Zeny (Orgs.). Geografia Cultural: um século (3). Rio de Janeiro: EdUERJ, 2002.

CARA, R. B. Territórios de lo cotidiano: puntos de partida para La reflexión. In: MESQUITA, Z.; BRANDÃO, C. R. Territorios de lo cotidiano: uma introdução a novos olhares e experiências. Ed. UFRGS/UFISC, 1995. PP. 6775.

CARLOS, Ana F. A. A geografia na sala de aula. São Paulo: Contexto, 2000.

O espaço urbano: novos escritos sobre a cidade. São Paulo: Contexto, 2004.

CARVAlHO, V. S. A República Velha em Itabaiana. Aracaju: Fundação Oviêdo Texeira, 2000.

Santas Almas de Itabaiana Grande. Itabaiana, 1973. (Edições O SERRANO).

CASTELLS, M. O poder da identidade. São Paulo: Paz e Terra, 1999.

CLAVAL, P. A Geografia Cultural. Florianópolis: Editora da UFSC, 1999.

O papel da nova geografia cultural na compreensão da ação humana. In: CORREAA, R. L \& ROSENDAHL, Z. (Orgs.). Matrizes da geografia cultural. Rio de Janeiro: Editora da UERJ, 2001.

CORREAA, R. L. ROSENDAHL, Z. (Org.). Introdução à Geografia Cultural. Rio de Janeiro: Bertrand Brasil, 2003. 
DEMATTEIS, Guiseppe. Sistema local territorial (SLOT): Um instrumento para representar, ler e transformar o território. In: ALVES, A.F; CARRIJO, B. R; CANDIOTTO, L. Z. P. (Orgs.). Desenvolvimento territorial e agroecologia. $1^{\text {a }}$ Ed. São Paulo: Expressão Popular, 2008, pp. 33-46.

FELIPE, José Lacerda. A (Re)Invenção do Lugar: Os Rosados e o "País de Mossoró". Revista Território, Rio de Janeiro, ano VI, n. 10, pp. 33 - 49, 2001.

KOGA, D. Medidas de cidades: entre territórios de vida e territórios vividos. São Paulo: Cortez, 2003.

HAESBAERT, Rogério. Concepções de territórios para entender a desterritorialização. In: Território território. Niterói: PPGEO-UFF/AGB, 2002.

O Mito da Desterritorialização: Do "Fim dos Territórios" à Multiterritorialidade. Rio de Janeiro: Bertrand Brasil, 2004.

Região, Diversidade Territorial e Globalização. GEOgraphia, Ano. 1, no 1, p. $15-40,1999$.

HALL, Stuart. A identidade cultural na pós-modernidade. Rio de Janeiro: DP\&A, 2006.

Instituto Brasileiro de Geografia Estatística (IBGE) - Censos Demográficos, 1970 1991

Instituto Brasileiro de Geografia Estatística (IBGE) - Contagem da população de 1996.

Instituto Brasileiro de Geografia Estatística (IBGE) - Contagem da população de 2007.

MORELLI, Luiz Alberto \& SUERTEGARAY, Dirce M. A. Meio ambiente, território e identidade cultural- Estudo de caso da Aracruz celulose do RS. Anais..., Geografia: Ensino \& Pesquisa, Santa Maria, v. 13 n. 2, p. 430-435, 2009.

NEVES, Gervásio Rodrigo. Territorialidade, desterritorialidade, novas territorialidades (algumas notas). In: SANTOS, Milton; SOUZA, Maria Adélia. (Org.). Território: globalização e fragmentação.. São Paulo: Hucitec, 1994, v., p. 270-282. 
RAFFESTIN, Claude. Por uma geografia do poder. Tradução de Maria Cecília França. São Paulo: Ática, 1993.

SANTOS, Milton. Espaço e método. São Paulo: Nobel, 1985.

- Metamorfoses do espaço habitado: fundamentos teóricos e metodológicos da Geografia. São Paulo: Hucitec, 1996.

SANTOS, Milton; SOUZA Maria Adélia A de; SILVEIRA Maria Laura (Orgs.). Território: globalização e fragmentação. HUCITEC, 1994.

SAQUET, Marcos Aurélio. Abordagens e concepções de território. São Paulo: Expressão Popular, 2007.

Por uma abordagem territorial. In: SAQUET, M. A. \& SPOSITO, E. S. (Orgs.). Territórios e territorialidades: Teorias, processos e conflitos. $1^{\mathrm{a}}$ ed. São Paulo: Expressão Popular, 2009. PP. 73-94.

SAQUET, M. A. \& SPOSITO, E. S. Território, Territorialidade e Desenvolvimento: Diferentes perspectivas no nível internacional e no Brasil. In: ALVES, A.F; CARRIJO, B. R; CANDIOTTO, L. Z. P. (Orgs.). Desenvolvimento territorial e agroecologia. $1^{\text {a }}$ Ed. São Paulo: Expressão Popular, 2008, pp. 15-32.

SILVA, L. C. S. Olericultura e trabalho familiar em Itabaiana-SE. Dissertação de mestrado: Núcleo de pós-graduação em Geografia, UFS, 2001.

TUAN, Yi-Fu. Topofilia: Um estudo da percepção, atitudes e valores do meio ambiente. São Paulo: Difel, 1980.

Recebido para publicação em julho de 2009 Aprovado para publicação em dezembro de 2009 